Revista Internacional de Sociología (RIS)

Vol.67, No 3, Septiembre-Diciembre, 559-588, 2009

ISSN: 0034-9712

elSSN: 1988-429X

DOl:10.3989/ris.2007.02.15

\title{
¿DISIDENCIA DENTRO DEL FEMINISMO?
}

\section{DISSIDENCE WITHIN FEMINISM?}

\author{
Ana LeÓn Mejía \\ Instituto de Estudios Sociales Avanzados, (IESA-CSIC), Córdoba, España \\ aleon@iesa.csic.es
}

\section{RESUMEN}

En este trabajo se examina una nueva corriente de pensamiento surgida dentro del movimiento feminista norteamericano, que disiente de algunos de los principales presupuestos epistemológicos del feminismo, y que denuncia sus efectos, tanto en la población americana, en especial dentro de la comunidad académica, como en la agenda pública. Las autoras que han emprendido la crítica de la denominada "ideología del género" cuentan por un lado con el apoyo de una gran parte del público americano. Por otra parte, han suscitado la ira del feminismo académico que les atribuye ser parte de un backlash (un contraataque) frente a los logros conseguidos por el feminismo. Son acusadas, entre otras cosas, de conservadurismo, traición a la causa feminista o acoso institucional antifeminista. El grado de crispación se ha elevado con la crisis de "las violaciones en las citas" que se ha convertido en la nueva causa feminista, junto con las actuales políticas contra la pornografía y el acoso sexual. A todo esto, se añade el surgimiento de voces disidentes en Canadá, Francia y España, que confirman una grave fractura dentro de uno de los movimientos sociales más importantes de las últimas décadas.

\section{Palabras Clave Adicionales}

Acoso, Ideología del género, Feminismo disidente, Violación en una cita, Violencia.

\section{Abstract}

The aim of this paper is to examine the dissident thought within the feminist movement. This new approach dissents from some main epistemological assumptions of the feminism, and claims against its effects, both in the academy and the public agenda. On the one hand, the authors that have leaded the critique against the so-called "gender ideology", have the support of most of the American public. On the other hand, they are experiencing the wrath of the academic feminist and the accusation of being part of a backlash. The charges are conservatism, betrayal, and anti-feminism harassment. The social tension has increase with the date rape crisis, the new feminism cause, besides the current politics against pornography and sexual harassment. Furthermore dissident voices in Canada, France and Spain prove a serious break up in one of the most important social movements in the last decades.

\section{Additional KeYwords}

Date Rape, Dissident Feminism, Gender Ideology, Harassment, Violence. 


\section{INTRODUCCIÓN ${ }^{1}$}

El feminismo norteamericano se debate con un nuevo adversario en su lucha contra la sociedad patriarcal. Se trata del trabajo de un grupo de feministas académicas norteamericanas, que acusan al movimiento por la liberación de las mujeres de falsear la realidad, y de haberse convertido en la práctica en un movimiento de victimización. Señalan también, que gran parte de la investigación feminista carece de rigor cientifico y está imbuida, y demasiado contaminada, por la ideología feminista. Afirman que estas deficiencias de calidad se trasladan a los estudios de mujer de las universidades, cuyos contenidos son limitados por la censura de la corrección política feminista que opera en ellos (Patai, 2003). Culpan al feminismo de haber creado un estado de alerta y crispación con la extensión de la definición de los conceptos de acoso y agresión sexual más allá del sentido común (Paglia, 1992 y 2001; Patai, 2003; Sommers, 1994).

Esta situación tan extrema comienza a ser achacada a la denominada "ideología del género". Las feministas de la disidencia han roto un silencio contenido con críticas que arremeten contra conceptos transversales del feminismo: la sociedad patriarcal, la dominación masculina, la violencia de género, etc. No tienen miedo de encararse con muchas de las teóricas más ilustradas y conocidas del panorama feminista no sólo nacional sino también mundial: Naomy Wolf, Susan Faludi, Gloria Steinem, Catherine MacKinnon, Andrea Dworkin, Marilyn French, Shulamith Firestone, y una larga lista de mujeres que son de obligada referencia en cualquier curso feminista o de estudios de género. Están preocupadas sobre todo por la pérdida de legitimidad de un movimiento que se encuentra sumido en una grave crisis de percepción por parte de la población femenina, que no se considera feminista ni quiere identificarse con las feministas, aunque sí haya interiorizado los valores del feminismo y disfrute de los logros conseguidos por este movimiento (Aronson, 2003).

\section{EL PENSAMIENTO DE LA DISIDENCIA}

La calificación de este fenómeno como disidencia aparece cada vez con más frecuencia en artículos, libros, blogs de Internet y páginas web que recogen las críticas hacia el movimiento feminista. Disidencia es también el término que se ha adoptado en esta investigación. El acto de disidir implica "la separación de la común doctrina, creencia o conducta",

\footnotetext{
${ }^{1}$ Quisiera agradecer a Luis Miguel Miller su incalculable ayuda en las correcciones al texto final y el apoyo personal sin el cual no hubiese sido posible escribir este artículo. A Fernando Aguiar, también por el tiempo que me ha dedicado, sus consejos, orientación y sus valiosos comentarios. Por último, mi agradecimiento a los evaluadores por sus correcciones. Las versiones anteriores de este trabajo han sido presentadas en el III Congreso Andaluz de Sociología (2006) y en el seminario del IESA-CSIC sobre nuevas corrientes del feminismo (2007).
} 
así como un "grave desacuerdo de opiniones" (RAE, 2006), que es justo lo que ocurre con las feministas críticas con el feminismo, que no por ello se sienten fuera del movimiento, sino que han dejado de comulgar con la corriente establecida o mainstream.

Dos autoras americanas fueron las primeras en abrazar la disidencia en la década de Ios noventa: Camille Paglia, con Sexual Personae, Art and Decadence from Nefertiti to Emily Dickinson (1990) y Christina Hoff Sommers, con Who Stole Feminism? How Women Have Betrayed Women (1994). Ambas autoras comenzaron a criticar el determinismo social del feminismo, en especial en los temas relativos a la violencia y la identidad sexual. Estas dos autoras se desmarcan así, de una concepción roussoniana del ser humano, benigno por naturaleza y corrupto por las fuerzas sociales, que domina en el feminismo. También se alejan de la visión feminista de uno de los aspectos fundamentales de movilización para este movimiento: la violencia de los hombres hacia las mujeres. En especial, en lo referido a la violación y a la denominada violencia de género.

Para el feminismo los determinantes sociales que configuran los roles de género son los responsables de que el hombre, por su socialización en el patriarcado, ejerza una violencia de género contra la mujer. Por tanto, si su naturaleza -en principio igual a la de la mujer- no fuera corrompida por los valores dominantes masculinos, no cometería tales actos. Pero desde un punto de vista analítico estas explicaciones no se sostienen sobre una argumentación consistente. Más bien el feminismo cae, en este sentido, en un tipo de explicación circular similar a la explicación funcional contestada metodológicamente por autores como Stinchcombe (1970) y Elster (1983). Una explicación funcional es aquélla en la cual las consecuencias de algún comportamiento 0 de algún ordenamiento social son elementos esenciales de las causas de ese comportamiento (Stinchcombe, 1970: 97). Así, el feminismo emplea las consecuencias derivadas del comportamiento de determinados hombres (discriminación y opresión contra la mujer, violencia de género, etc.) como causas del propio fenómeno que pretende explicar. Como ha señalado Elster (1983: 61), la explicación funcional puede ser sostenida en Biología, debido a que en esta ciencia es posible identificar un mecanismo de carácter general que posibilita la retroalimentación del sistema funcional en cuestión: la teoría general de la evolución. Sin embargo, dicho mecanismo general no existe en las ciencias sociales.

Para estas dos autoras, por lo tanto, no es la sociedad (patriarcal) ${ }^{2}$ la fuente de violencia, ni el género de los hombres el único factor, puesto que no contamos con una explicación causal satisfactoria que demuestre dicha relación. Tampoco opinan -como algunas líderes del movimiento feminista- que vivamos en una época especialmente hostil donde la mujer sea víctima de una guerra no declarada (Faludi, 1991), sino que defienden que la sociedad, a través de la educación y la inculcación de valores, trata de combatir ésta y otras formas de violencia. Y además sostienen que la línea histórica de

\footnotetext{
${ }^{2}$ El patriarcado aparece en los escritos feministas como ese mecanismo causal que explica todas las desigualdades de género. Sin embargo, la ausencia de una definición analítica de este concepto hace que se haya convertido en la causa y consecuencia de todo comportamiento discriminatorio.
} 
desarrollo de las sociedades ha conducido a condenar éticamente la agresiones contra las mujeres o contra cualquier individuo, y no a perpetuar o agravar la discriminación y la violencia, es decir, que nos encontramos en la actualidad en un estadio más avanzado en este aspecto. Ambas autoras examinan detenidamente éste y otros fenómenos, y sus dos obras -emblemáticas en esta denominada disidencia- son las responsables de la brecha ideológica. Christina Hoff Sommers parte de un punto de vista más empírico, analizando la metodología empleada a la hora de elaborar cuestionarios destinados a medir la violencia contra las mujeres, y comparando las cifras sobre violencia de género arrojadas por diversas fuentes. Camille Paglia se adentra en este tema desde una posición más teórica, que analiza la naturaleza de los conflictos de género plasmados en el arte y la literatura occidental. Tanto Paglia como Sommers rechazan la actitud victimista del feminismo, que presenta a la mujer como un ser vulnerable -siempre en peligro y sometido a la dominación masculina- $y$ al hombre como un ser violento, un agresor en potencia que mantiene oprimida a la mujer en todos los aspectos de las esferas pública y privada.

Además de estas dos pensadoras, son varias las autoras que podrían denominarse disidentes 0 así han sido catalogadas por diferentes analistas ${ }^{3}$. Dentro del feminismo hay intelectuales con una brillante personalidad, cuyas tesis originales se desvían del feminismo convencional. Pero la disidencia, entraña algo más que una mera controversia o una habilidad para abordar temas candentes y comprometidos que sean capaces de suscitar polémica. Para que consideremos disidente el pensamiento de una determinada autora feminista, éste debe alejarse lo suficiente de algún dogma oficial incuestionable por el feminismo. Por ejemplo, dudar de la existencia de una dominación masculina, desechar la convicción de que vivimos en una sociedad patriarcal o defender que el género no es una categoría únicamente social. Alguno de los puntos comunes de las feministas disidentes son el rechazo de la politización de lo personal, la victimización de las mujeres como sexo oprimido y el proteccionismo paternalista de algunas políticas estatales exigidas por el feminismo del género; se denuncia asimismo la presencia de una ideología anti-masculina o ginecentrista dentro del feminismo, así como el impacto de ésta en la agenda y las políticas públicas. Reivindican un feminismo liberal y equitativo no obsesionado con las diferencias de género y las diferencias de poder. Si bien es cierto

\footnotetext{
${ }^{3}$ Varias mujeres y hombres han desatado la furia del feminismo establecido con sus obras incendiarias: Cathy Young (1999), Daphne Patai (1998), Katie Roiphe (1994b), Waren Farell (1986; 1993), Donna Laframboise (1996), Karen Lehrman (1997), Wendy Kaminer (1990), Chesler (2006) o Rita Simon (1995), entre otras. Otras feministas que han despertado el interés público proceden de la derecha americana. Defienden los valores tradicionales americanos y religiosos, por lo que no las hemos considerado dentro de esta disidencia, pues aunque la posición ideológica de una determinada autora no es un elemento que haya que tener en cuenta, las autoras que aquí analizamos deben haber pertenecido en un momento inicial al movimiento feminista de la segunda ola (de carácter progresista), o bien encuadrarse dentro de este movimiento aunque no comulguen con los presupuestos teóricos desarrollados principalmente en los setenta (como ocurre con Sommers) para ser catalogadas como disidentes.
} 
que no pretendemos recoger en este trabajo todas las obras u autoras disidentes (pues sin duda nos extralimitaríamos en espacio y contenidos) sí queremos, al menos, presentar las obras que suscitaron esta disidencia (de acuerdo al criterio que hemos introducido) y que tuvieron un papel más relevante en el surgimiento de esta fractura.

\section{AsPeCtos QUe SUSCITARON LA DISIDENCIA}

Christina Hoff Sommers, en su libro Who Stole Feminism?, no sólo se limita a una reflexión personal sobre el giro que el movimiento feminista ha dado en las últimas décadas, sino que argumenta con fuentes recabadas en su investigación contra aquellos puntos que critica de la "ideología del género", documentando caso por caso todos aquellos aspectos que denuncia.

La centralidad del género en el feminismo se enlaza con una concepción de las relaciones socialmente construidas entre hombres y mujeres marcadas por la dominación masculina. Las mujeres deben, pues, liberarse de la potestad de los hombres y batallar

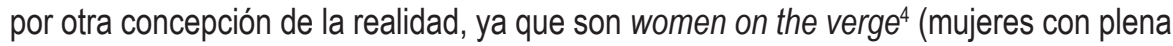
consciencia de su opresión) sumidas en un backlash ${ }^{5}$ (en un contraataque) contra lo femenino. El feminismo del género no sitúa el debate en términos de justicia y de lucha por una sociedad igualitaria - critican las feministas disidentes - sino que se levanta sobre la enemistad hacia el género masculino y la búsqueda de los intereses femeninos.

Para Christina Hoff Sommers, el feminismo actual se ha desvinculado de sus raíces humanistas y liberales, así como de sus metas iniciales: la lucha por la igualdad entre hombres y mujeres y la defensa de los derechos que deben disfrutar por igual ambos sexos. Distingue entre equity feminism (feminismo de la igualdad) y gender feminism (feminismo del género) o dicho de otra manera entre old feminism y new feminism (entre el viejo feminismo y el actual). El feminismo de la igualdad desea para las mujeres lo mismo que para cualquier persona: un tratamiento justo sin discriminaciones (Sommers, 1994: 22) pero sin privilegios. Sin embargo, el nuevo feminismo del género, que gira en torno a este concepto, tiene como finalidad acabar con un supuesto sistema vigente de dominación masculina o también llamado heteropatriarcado, "un complejo proceso en el cual las personalidades bisexuales infantiles son transformados en masculinas y

\footnotetext{
${ }^{4}$ Aunque su traducción literal es "estar al límite" o "al borde de un ataque" Sommers define esta expresión como "el permanente estado de las mujeres que sienten que han logrado adquirir una conciencia de la realidad de su situación en una sociedad dominada por los hombres" (Sommers, 1994: 47).

${ }^{5}$ Este es también el título de uno de los libros más famosos de Susan Faludi (1991). Este contraataque se ha producido tras los logros conseguidos por el feminismo y consiste en la acusación de radicalismo, anti-masculinidad o falta de rigor, que según ellas son emitidas desde el sector conservador y antifeminista. Este presupuesto es peligroso, pues toda crítica es considerada de esta manera como parte del backlash. Ambas expresiones "women on the verge" y "backlash" aparecen con frecuencia en el discurso feminista 0 son utilizadas como licencias retóricas en artículos de prensa, ensayos, etc.
} 
femeninas, unas destinadas a disponer y otras a obedecer" (Sommers, 1994: 22). Por tanto, la lucha contra esto último requiere, para el feminismo del género, de medidas y protecciones especiales para las mujeres. Mantienen, entre otros aspectos, que el punto de vista de las mujeres (intrínsicamente diferente del de los hombres) y que ha sido largamente desestimado ha de encontrar ahora su propia vía de expresión, y para ello, es necesario disponer de recursos económicos que permitan, entre otras cosas, realizar investigaciones con enfoque de género (gender studies), levantar espacios propios como los centros de estudios de la mujer, así como dotar a la universidad de una oferta académica propia (cursos de especialización, master, doctorados, seminarios, etc.). Sin embargo, lo que podría ser contemplado como un fenómeno positivo ha desembocado para Sommers en situaciones denunciables.

La primera de ellas consiste en la manipulación de datos, estadísticas, cifras y estudios, que tienen como fin mediatizar la violencia que sufren las mujeres, para recabar una mayor atención pública y justificar su cruzada contra el patriarcado. En su libro se analizan críticamente algunos de los estudios sobre violación y sobre violencia doméstica más conocidos. La segunda de ellas, the curriculum transformation, resulta no menos preocupante, sobre todo para la comunidad académica, ya que se trata de reformar los planes de estudio universitarios y el contenido de las materias enseñadas en el sistema educativo ${ }^{6}$. Veamos algunos de los fenómenos que analiza esta autora.

\section{Nobles MentiRas}

Uno de los capítulos del libro de Christina Hoff Sommers, titulado Noble Lies, denuncia la utilización de estadísticas por parte del feminismo a la hora de hablar de algunos de los problemas que afectan a las mujeres. La manipulación de las cifras sobre trastornos alimenticios, violencia doméstica, violación o el problema de las diferencias salariales, son mentiras nobles ${ }^{7}$ para el feminismo del género. Ya en el prefacio de su libro, Sommers nos presenta tres ejemplos que captaron su atención. En Revolution from Within, de Gloria Steinem, conocida feminista americana, se afirmaba que 150.000 mujeres morían de anorexia cada año. Este dato, que a primera vista resultaba cuando menos desconcertante, se remitía al conocido libro de Naomy Wolf The Beauty Myth, donde se califica esta

\footnotetext{
${ }^{6}$ Hemos dejado de lado otros aspectos analizados por Sommers por la estructura misma de este artículo así como la otra obra más conocida de esta autora, The War against Boys (2001), que trata sobre las dificultades que afectan a los chicos en el actual sistema educativo y que ha sido recientemente traducida al castellano.

${ }^{7}$ El concepto de "mentira noble" se remonta a Platón y puede encontrase en La República al final del libro II y comienzo del III, donde se discute acerca de la naturaleza de la verdadera mentira (la que profesa un particular) -que es deleznable- y la mentira que puede ser lícita para los sabios gobernantes si ésta beneficia a la comunidad (mentira noble). El libro de Sommers, que irritó notablemente a muchas feministas, ha sido admirado y vapuleado igualmente por estas denuncias de fraude y error. Laura Flanders (1994) acusó a Sommers de mentir en su libro, a lo que Sommers (1995) respondió contra -argumentando de nuevo.
} 
mortalidad de holocausto o femicidio. La fuente de esta estadística era un informe sobre la anorexia de la directora del departamento de Women's Studies de la Cornell University, quien a su vez afirmó basarse en los datos recogidos por la Asociación Americana para la Anorexia y la Bulimia. Sin embargo, el presidente de esta asociación desmintió la cifra aclarando que ésta no se refería a mortandad, sino a casos de padecimiento de la enfermedad. El número real de muertes era de 70. Esta cifra, por sí misma lamentable, había sido elevada sin que nadie dudara de la veracidad del hecho, con el añadido de que siguió siendo citada aun después de su desmentido (en el libro de Sommers, quien además le hizo constar su descubrimiento a Wolf). $Y$ debemos decir que en las versiones en castellano, posteriores a la publicación del libro de Sommers, la cifra incorrecta se ha seguido manteniendo (Steinem, 1995; Wolf, 1991).

Encontramos otro hecho similar en la afirmación aparecida en un boletín de la Nacional Women's Studies Association acerca de que la violencia doméstica producía por sí sola más defectos de nacimiento que otras causas combinadas. Cuando Sommers quiso hacerse con este estudio, se encontró con que no existía, a la par que los periodistas más prestigiosos de la prensa nacional seguían haciéndose eco de la noticia. Tras indagar en el origen de este dato halló que la versión original se refería a cómo se prestaba más atención médica a un problema que a otro. Sin embargo, lo más interesante de este fenómeno — aparte de la tergiversación producida - era comprobar la falta de cuestionamiento de estos datos proporcionados por mujeres y asociaciones feministas. Otro bulo desmontado por la autora se hizo eco de una noticia aparecida en prensa y televisión, en la que se alarmaba a la población informando de que el día de la Super Bowl el índice de maltrato se elevaba en un $40 \% 8$. Tan sólo un periodista del Washington Post, Ken Ringle, cuestionó este dato hallando rápidamente que no existía ninguna base real para tal afirmación (Sommers, 1994). En su investigación Sommers se encontró con este fenómeno en los estudios sobre violencia de género. En primer lugar, comparó cifras sobre victimización, dándose cuenta de cómo una misma fuente proporciona estadísticas de víctimas por millón y por segundo, que resultan incompatibles entre sí (Sommers, 1994: 192-194). Y más adelante enfocó su atención en la metodología empleada a la hora de medir los niveles de violencia doméstica.

Gelles y Strauss, de la Universidad de Rhode Island y New Hampshire, fueron pioneros en medir la violencia del género en EE.UU y sus fuentes eran recogidas por el gobierno, la policía y el FBI. Pero estos científicos sociales se ganaron la enemistad de las feministas, a finales de los setenta, al no reconocer al patriarcado como la causa del

\footnotetext{
${ }^{8}$ En este sentido, las feministas del género no son muy originales. En el campo de la publicidad y el marketing norteamericano es bien conocido que la final de la Super Bowl se convierte en el mejor reclamo para llamar la atención de los consumidores. Este evento anual transciende lo meramente deportivo para convertirse en uno de los rituales más importantes en los que participa la sociedad norteamericana contemporánea. "Según el vicepresidente de marketing de Walt Disney, la Super Bowl realmente es la convocatoria de los hombres, mujeres y niños americanos, que se reúnen para participar en un ritual anual'” (Chwe, 2001: 11).
} 
maltrato. Estos investigadores se encontraron con que también había hombres maltratados (aunque resaltaban que las mujeres eran mucho más proclives a ser heridas y necesitar asistencia) y, además, en los niveles de violencia dentro de las familias norteamericanas, (maltrato infantil o a personas mayores) las mujeres estaban tan involucradas como los hombres. Incluso se halló que a menudo la principal fuente de violencia de la familia provenía de algún hermano. Además, distinguían entre violencia menor y mayor (que requería asistencia media). Según sus datos, la mayoría de las familias americanas sólo incurría en violencia menor y menos de $1 \%$ en tipos de violencia más graves. Estos datos son muy distintos de los ofrecidos por las feministas del género, que tampoco se hicieron eco de otros descubrimientos, como el de que había habido un descenso en el número de mujeres maltratadas de 1975 a 1985.

Otros estudios sobre el maltrato y la violencia que no han recibido la atención que merecen, por alejarse de la visión feminista, son aquellos que señalan que se producen tasas de maltrato en las parejas del mismo sexo similares a las producidas en las heterosexuales. En EEUU se produjeron entre un $25 \%$ y un $33 \%$ de abusos en parejas de lesbianas, gays, bisexuales y transexuales, un porcentaje similar al de las parejas heterosexuales (NCAVP, 1998). Por tanto, parece que el maltrato está muy relacionado con trastornos dentro de las relaciones de intimidad o intimate partner violence ${ }^{9}$ que no tienen en el género su único componente (Bethea et al., 1999; Paik, 1999; Coleman, 1994 y Renzetti, 1988).

\section{LA TRANSFORMACIÓN CURRICULAR}

Para aproximarnos al concepto de curriculum transformation o transformación de los contenidos educativos y los planes de estudio mediante la inclusión de la perspectiva de género, vamos a remitirnos a la información procedente del National Center for Curriculum Transformation Resources on Women:

Desde finales de 1970 profesores e investigadores feministas han estado examinando el curriculum tradicional en la educación superior en lo relativo a los prejuicios raciales y de género. Al mismo tiempo que las nuevas enseñanzas sobre estudios de la mujer se volvían cada vez más abundantes y accesibles, el profesorado ha sido asistido en revisiones y discusiones a través de proyectos de desarrollo universitario, comúnmente denominados como curriculum transformation projects. El objetivo de estos proyectos es alentar al profesorado a valerse de los nuevos estudios sobre la mujer en sus cursos tradicionales para lograr un currículo más equilibrado.

El esfuerzo necesario por eliminar los estereotipos de género, los sexismos lingüísticos y

\footnotetext{
${ }^{9}$ Este término (IPV) ha comenzado a imponerse, al menos en el ámbito de la investigación, sobre otras expresiones como violencia de género o violencia machista.
} 
otorgar más visibilidad a las mujeres en todos los campos, se deforma hasta puntos que despiertan la alarma en muchos docentes. Convencidas de hallarse en la vanguardia de una batalla de dimensiones históricas, pretenden reescribir la historia y cambiar el canon occidental. Las feministas del género claman que la Historia ha sido hasta ahora His Storie (la historia de ellos) y que, por tanto, nos ha llegado deformada por la dominación masculina en la política, la ciencia y el arte (Sommers, p. 58). Se proponen pues, elaborar Her Storie (la historia desde el punto de vista de las mujeres). Para Sommers la historia no puede ni debe reinventarse, no le corresponde convertirse en un arma ideológica. Es necesario rescatar aquellos aspectos que hayan quedado relegados a un segundo plano de manera injusta o bien recuperar a las mujeres que no hayan recibido la atención que merecen. Pero hay un hecho evidente y lamentable que es imposible de ignorar: y es que las mujeres no han tenido la misma oportunidad de hacer historia y participar en los campos políticos y militares, que han promovido el cambio social, en la medida en que sí pudieron hacerlo los hombres. Sommers habla de la estrategia feminista filler feminism, consistente en ocupar espacios en los libros de textos con hechos feministas acordes con las enseñanzas que se desean impartir (p. 60), "acentuando la importancia de personajes femeninos y hechos menos importantes que reducen la cobertura a personajes y hechos sí relevantes del panorama histórico americano" (Lerner y Nagai, 1995: 55-68); de manera que los estudiantes conocen mejor a Harriet Tumban (una afroamericana que luchó contra la esclavitud) que a George Washington, Lincoln o Churchill, y tienen más conocimientos sobre el papel que las mujeres desempeñaron trabajando en las fábricas durante la Segunda Guerra Mundial, que sobre la Gran Depresión americana ${ }^{10}$.

En el campo de las artes, donde la ausencia histórica de la mujer es una lamentable realidad, las feministas del género afirman que las obras de arte realizadas por mujeres pasaron desapercibidas porque los estándares siempre fueron fijados a favor de los hombres (Sommers, 1994: 63). Por tanto, habría que revisar esos criterios de excelencia para que las mujeres llegasen a una posición de igualdad. Pero la realidad nos devuelve al hecho de que pocas mujeres en la Antigüedad, la época Medieval, el Renacimiento o la Modernidad, pudieron dedicarse al arte como lo hicieron los hombres. No se trata de los criterios del canon artístico, sino de la ausencia de la inmensa mayoría de las mujeres en cualquier esfera que no fuese la doméstica en el transcurso de los siglos. Tal y como afirma Camille Paglia, "el feminismo no ha encontrado ni una gran pintora o escultora que añadir al canon, ha reanimado la reputación de muchas mujeres menores que no necesitaban ser redescubiertas" (Paglia, 2001: 195). Si ha promovido, por el contrario, la crítica y retirada de cuadros e imágenes cuyos desnudos femeninos ejemplifiquen la mirada masculina bajo la que fueron creados y para la que fueron creados porque el arte es en definitiva un fruto más del patriarcado. Y además, crean un ambiente sexual hostil que puede ser denunciado aunque se trate de la mismísima Maja Desnuda de Goya (Sommers,

\footnotetext{
${ }^{10}$ Resultados obtenidos en la Primera Evaluación Nacional del Progreso educativo (Ravitch y Finn, 1987) citado en Lerner y Nagai (1995: 55).
} 
1994: 270; Paglia, 2001: 110). Este cuadro fue retirado a petición de la profesora Nancy Stumhofer de la Universidad de Pennsylvania, que expresaba de la siguiente manera el sentimiento que le inspiraba esta obra de arte: "me sentí como si estuviera tumbada allí, desnuda, expuesta y vulnerable. Después de que pasara mi bochorno me sentí indignada pensando que ninguno de mis colegas ni de mis estudiantes masculinos se encontrarían alguna vez en esa situación" (Sommers, 1995) ${ }^{11}$.

Otro aspecto que Sommers analiza del feminismo es la propia epistemología sobre la que se sostiene su producción teórica. Como ya se ha dicho, gira en torno a los conceptos transversales de género, patriarcado y dominación masculina, que aparecen continuamente en el discurso feminista, frecuentemente de manera ideológica o retórica en lugar de analítica. Así pues, todo lo masculino es sospechoso y todo lo neutro es sospechosamente masculino, incluido el conocimiento ${ }^{12}$. En este sentido, Sommers recoge algunas de las valoraciones feministas sobre el conocimiento y la cultura:

- La idea de genialidad es sospechosa de elitista y masculina, y en el mundo de la enseñanza literaria, por desgracia, sólo se contemplan a unos pocos genios. Para la americana Peggy McIntosh ${ }^{13}$, favorable a desechar las jerarquías de excelencia masculina, Leo Tolstoi no tendría por qué recibir mayor atención que una novelista del siglo XX como Margaret Atwood o Alice Walter (Sommers, 1994: 65), puesto que su genialidad reside en haber logrado una distancia con respecto al resto de autores, siendo éste un criterio masculino, jerárquico e inaceptable. En lo que no ahonda es en explicar por qué determinados autores consiguen alejarse de lo ordinario, independientemente de que éste sea un criterio correcto o no para medir la excelencia.

- La feminista Elisabeth Fee afirma que "el conocimiento fue originado como un acto de agresión - la naturaleza pasiva debía ser interrogada, desvestida, penetrada y forzada por el hombre para revelar sus secretos" dónde lo dice, quién la cita (Sommers, 1944: 66). En esta línea se encuentran otras conocidas feministas americanas como Mary Ellman, Catherine MacKinnon y Sandra Harding. Para MacKinnon (1993), los hombres se apropian de la naturaleza, como los violadores de la mujer, y para ellos el acto de conocer se asocia al de fornicar. Harding (1996) llama a los Principios de mecánica de Newton, "El manual de violación de Newton" (1996: 100)14.

\footnotetext{
${ }^{11}$ Este incidente despertó la atención de muchos intelectuales norteamericanos ya que ejemplifica el concepto de acoso que se maneja en EEUU (que incluye la presencia de imágenes degradantes o pornográficas en un centro de trabajo), la moralidad sexual que se ha impuesto desde el mainstream feminista y su capacidad de actuación, así como las controversias surgidas en la comunidad universitaria acerca de la libertad de expresión en contraposición a las políticas de control y regulación.

${ }^{12}$ Recordemos la crítica al feminismo como explicación funcional realizada anteriormente.

${ }^{13}$ Directora asociada del Centro Wellesley para la Mujer, fundadora y codirectora del Centro Nacional SEED. (Seeking Educational Equity and Diversity), comprometido con los currículum inclusivos.

${ }^{14}$ No tiene desperdicio la lectura del capítulo V, ¿La historia y la filosofía de la ciencia deben recibir una clasificación X?, donde no sólo habla de Newton, sino de las metáforas de violación y tortura en Bacon o Copérnico. Cabe mencionar que éste es un libro de obligada mención en cualquier curso de doctorado 0
} 
Además, las feministas del género defienden que la condición de opresión que afecta a las mujeres las convierte en mejores conocedoras que los hombres; su manera de sentir más profunda les lleva a percibir y entender de mejor manera la realidad. Es decir, tienen una ventaja epistémica con respecto a los hombres (Sommers: 1994: 74; Harding, 1996) ${ }^{15}$. Reflexiones de este tipo, acerca de la superioridad femenina en ciertos aspectos, son las responsables de que el feminismo comience a ser tachado de ginecentrista.

La pedagogía feminista es otro de los aspectos que se analizan en el libro Who stole feminism, al estar íntimamente relacionado con el sistema educativo americano. Las clases feministas son calificadas por sus profesoras como espacios de una nueva conciencia revolucionaria de liberación personal, donde pueden darse rienda suelta, a través de sesiones de auto-psicoanálisis, talleres de narrativa y performances, a los sentimientos de rabia, miedo, erotismo o frustración que el patriarcado reprime (Sommers, 1994: 88). La pedagogía feminista del género niega los ideales de verdad objetiva y enseñanza desinteresada. Toda enseñanza es una forma de adoctrinamiento al servicio de la clase política dominante (masculina) y los planes de estudios universitarios no son sino men's studies (Sommers, p. 96), diseñados para mantener y reforzar el sistema patriarcal. El feminismo del género concibe la enseñanza como un instrumento político más al servicio del patriarcado y, por tanto, es legítimo hacer lo mismo desde la postura feminista. Sommers en este sentido recoge una explicación de lo que según el filósofo Roger Scruton diferencia el adoctrinamiento de la educación (Sommers, 1994: 96):

- En una clase educativa los alumnos deben aprender métodos analíticos y herramientas críticas para aproximarse a la realidad. Asimismo, es deseable el desarrollo de actitudes de cuestionamiento y pensamiento independiente.

- En un curso de adoctrinamiento, las críticas son presentadas de antemano y las conclusiones asumidas con anterioridad. Scruton denomina este hecho como foregone conclusion (conclusiones extraídas de antemano). Las discrepancias y el escepticismo crítico en curso de adoctrinamiento son concebidos como fruto de la ignorancia, o en peor instancia, de la perfidia y el acoso.

El adoctrinamiento feminista se da, pues, dentro de un sistema cerrado e inmune a las críticas, gobernado por códigos invisibles de expresión, opiniones y comportamientos aceptables (Paglia, 2001: 177). En algunos casos extremos las críticas de los alumnos hacia las lecciones son interpretadas por los profesores como comportamientos hostiles y conflictivos, que han llegado a denominarse como antifeminism harassment o acoso hacia el feminismo (Sommers: 113-116). Esta acusación es trasladada también al profesorado que discrepa de los contenidos y la metodología feminista empleada en las aulas. Así,

máster de género.

${ }^{15}$ Éste es un claro ejemplo de ginecentrismo y de circularidad en una explicación. 
surgen otras expresiones como antifeminism intellectual harassment (acoso intelectual antifeminista), que alude a la creación de un ambiente hostil en la academia por parte de varios grupos (Patai, 2000); o también, sexismo sistémico (Patai, 2000) que es el sexismo institucionalizado en la enseñanza y en otras esferas públicas. Otros autores simplemente defienden que existe antifeminismo en la Universidad (Clark et al., 1996). En reacción a esta situación surgieron dos sitios web que levantaron la polémica (Patai, 2003) entre los partidarios de la vigilancia de la expresión (speech codes) y los firmes defensores de la libertad de expresión (free speech). Estos fueron: Nolndroctination.org y Campus Watch. El primero de ellos fue fundado por padres de alumnos preocupados por "el poder de la agenda sociopolítica para cambiar la orientación y el contenido de los cursos universitarios".

Para comprender esta situación debemos recoger la definición del acoso antifeminista que ha propuesto el comité sobre el estatus de la mujer, de la Asociación de Lengua Moderna: ${ }^{16}$

- Desestimación de escritoras, ensayistas y periodistas feministas.

- Desprecio del trabajo feminista como limitado, parcial y falto de rigor.

- Humor malicioso en contra de las feministas.

La peligrosidad de esta definición radica en que cualquier crítica podría ser entendida como un acto de perfidia o malevolencia contra el feminismo en sí, amén de formar parte del backlash, como así ha ocurrido con las críticas emitidas por las feministas disidentes. Los puntos de vista contrarios a la visión establecida desde el feminismo del género, que han surgido en las últimas dos décadas, son sistemáticamente descalificados como antifeministas, y sus representantes son acusados de conservadurismo y alineados despectivamente con la "nueva derecha" 17 (Gelb, 2006; Page, 2006; Duffy, 1992; Ebert, 1996). Surge así, el temor a ser políticamente incorrecto e incluso el riesgo de ser víctima de boicots ${ }^{18}$.

\footnotetext{
${ }^{16}$ Citado en Sommers (1994: 116). The Modern Language Association (MLA) cuenta con dos comités, uno sobre literatura negra y otro sobre el estatus de la mujer, que investiga la situación de la mujer dentro de la profesión, así como el estudio y enseñanza de la literatura femenina: http://www.mla.org/resources/committees/ comm_professional/comm_women

${ }^{17}$ En el caso de Paglia, que se define a sí misma como una lesbiana declarada, defensora a ultranza del aborto, la pornografía, la sodomía o la legalización de la prostitución, resulta llamativo que se la califique como "derechista" y reaccionaria.

${ }^{18}$ Ejemplos de rechazos, amenazas y repudio del feminismo del género hacia las voces críticas pueden verse relatados en los libros de Sommers (1994) y Paglia (2001). Kurtz (2001) narra otro ataque experimentado por Sommers en una Conferencia a la que fue invitada.
} 


\section{DATE RAPE. UNA NUEVA VISIÓN DE LA VIOLACIÓN Y DE OTRAS FORMAS DE AGRESIÓN SEXUAL}

Las date rape, o violación en las citas (cuando dos personas quedan para salir juntos), es un fenómeno surgido en la sociedad americana y denunciado por las jóvenes feministas de los campus universitarios. Es allí donde, afirman, sucede un tipo de violación que presenta una peculiaridad especial. La violación es una agresión sexual en la que se fuerza con violencia a una persona para tener relaciones sexuales en contra de su voluntad. Sin embargo, las violaciones en las citas engloban en su definición encuentros sexuales entre conocidos, producidos bajo la mediación de drogas, como el alcohol o los "porros" o bajo una coacción verbal: la insistencia del chico a la chica para tener una relación sexual. Si una mañana alguna chica se levanta con una fuerte resaca y con un chico al lado con el que no deseaba acostarse, pero con el que accedió fruto de su borrachera, ha sido victima de una violación. Si ha tenido una relación sexual no satisfactoria y de la que no estaba segura de querer tener, pero a la que cedió por voluntad propia motivada por la insistencia del chico, también es violación.

Esta realidad difícilmente comprensible fuera de EEUU ha desatado la alarma en todos los sectores sociales norteamericanos y ha fomentado la histeria en las adolescentes que dejan por primera vez sus casas para comenzar su andadura universitaria. En Norteamérica se han levantado enormes centros de asistencia en los campus y se han creado comités de buenas conductas sexuales. El nivel de ansiedad se ha disparado entre muchas jóvenes, hasta el punto de organizar marchas y encuentros anuales en los campus bajo el lema Take Back the Night ${ }^{19}$ (recupera la noche). Las víctimas son "supervivientes" y sus compañeras co-supervivientes que también sufren y necesitan asistencia. Son violadas potenciales y sus compañeros masculinos, potenciales violadores (Sommers, 1994: 218). Camille Paglia tacha este fenómeno de "superampliación alucinatoria de la violación para cubrir todos los encuentros sexuales desagradables o incómodos" (Paglia, 2001: 75). Roiphe califica la violación como catch-all (un cajón de sastre) donde cabe todo lo desapacible y molesto acerca de las relaciones entre los sexos (1994b: 80). Katie Roiphe quien vivió la crisis en su propio campus, en Princeton, escribió como consecuencia de ello The Morning After: Sex, Fear, and Feminism on Campus, donde critica el punto de vista de las feministas del género que había provocado un estado de histeria entre las universitarias. A partir de su propia investigación comprobó que la intuición que le llevó a la misma era cierta: no había indicios para afirmar la existencia de una escalada de

\footnotetext{
${ }^{19}$ El origen de estas marchas tuvo lugar en Inglaterra en 1977 y en EEUU en 1978 y su objetivo era la protesta por la inseguridad que sufren las mujeres en las calles durante la noche, momento en el que se producen la mayoría de agresiones sexuales. El fenómeno de las date rape, que recuperó estas marchas para denunciar este tipo de asalto sexual que ocurre en los campus, surgió como tal a principios de los noventa coincidiendo con la aparición de las primeras denuncias contra la ideología del género, y en la actualidad sigue ocupando un lugar central en la agenda norteamericana. Las marchas Take back the Night se han institucionalizado y son un evento frecuente en la vida de los campus americanos.
} 
violaciones en los campus universitarios. Entre 1982 y 1993 habían sido denunciadas a la policía dos violaciones en Princeton y descubrió que los chicos eran víctimas en mayor frecuencia que las mujeres de ataques violentos (Roiphe, 1994b: 47).

Una de las estadísticas más famosa y citada es aquella que afirma que una de cada cuatro mujeres experimentará en su vida una violación o algún tipo de agresión sexual. Esta cifra proviene de un estudio de la investigadora feminista Mary Koss, realizado de este contexto. Sommers refiere cómo Koss, quien había comenzado en los ochenta a desarrollar la Encuesta de Experiencias Sexuales (SES), publicó un artículo afirmando que la violación era el extremo de un continuum del comportamiento masculino normal en nuestra cultura:;2 su objetivo era identificar incidentes escondidos de violación no denunciados a la policía, así como trabajar de manera estandarizada con un instrumento que permitiese identificar diferentes tipos de victimización sexual (Fishen y Cullen, 2000). De modo que una versión revisada de la SES (Koss et al., 1985; 1987) ) $^{21}$ fue utilizada en un estudio nacional sobre mujeres universitarias. El resultado fue que un $53 \%$ de las universitarias había sufrido algún tipo de victimación sexual (desde la edad de 14 años) y un $11,9 \%$ había experimentado alguna forma de coerción sexual. Más grave aún resultaba la cifra de un $15.4 \%$ de mujeres que habían sido violadas y un $12.1 \%$ que habían experimentado un intento de violación. Es decir, según estos dos datos un $27.5 \%$ de las mujeres de la muestra había experimentado una victimación siguiendo la definición de violación del Estado de Ohio.

Lo curioso de este estudio era que el $73 \%$ las mujeres clasificadas como víctimas no se reconocían como tales, el $49 \%$ alegaron que fue falta de comunicación, un $14 \%$ lo catalogó como un delito o falta pero no de violación y un $11 \%$ no se sentían víctimas en absoluto. Además, un $42 \%$ de las víctimas tuvieron sexo con los supuestos atacantes en encuentros posteriores. Koss comparó sus resultados con los de la Encuesta Nacional del Delito, la NCVS (National Crime Victimation Survey), que se basaba en una definición más restrictiva de lo que constituía una violación. El resultado fue que la tasa de victimación seguía siendo de 10 a 15 veces mayor que la tasa basada en la NCVS (Fishen y Cullen, 2000). Para Koss esto solamente revelaba la ineficiencia mostrada hasta el momento en la medición de la agresión sexual. Sin embargo, para otros autores estos datos resultaban poco creíbles $^{22}$, sobre todo la formulación de las preguntas destinadas a medir la violencia sexual, en concreto, la número ocho de la encuesta que catalogaba la siguiente situación como violación:

"¿Ha mantenido usted relaciones sexuales sin desearlo debido a que un hombre la invitó a consumir alcohol o drogas?"

\footnotetext{
${ }^{20}$ Ver Koss y Oros (1982), citado en Fishen y Cullen (2000).

${ }^{21}$ Este estudio, encargado por Ms. Magazine, pasó a conocerse popularmente como Ms. Report (Warshaw y Koss, 1988).

${ }^{22}$ Las críticas partieron de Neil Gilbert (1991; 1995; 1998), Katie Roiphe (1994b) y del informe Toledo (1993).
} 
La pregunta número uno de la encuesta medía el intento de asalto sexual de esta manera:

"¿Alguna vez has consentido actividades sexuales cuando no querías porque estabas abrumada por los continuos argumentos y presiones de un hombre?"

Lo que se deduce de estas preguntas, según sus detractores, es que la mujer aparece como un ser vulnerable y sin capacidad de razonamiento, frente a un hombre que actúa con plena consciencia para llevar a cabo su acción:

La idea es que una mujer está demasiado borracha como para saber qué está haciendo mientras que el hombre puede mantenerse sobrio y lúcido. Si asumimos que las mujeres no son desvalidas ni tampoco ingenuas ellas deben mantenerse en la responsabilidad de su elección de haber bebido o consumido drogas (Roiphe, 1994a).

Esto conduce una perversa dicotomía de los sexos, "al mismo tiempo que todos los hombres son retratados como peligrosos depredadores la gran mayoría de las investigaciones sobre violencia sexual citadas convergen en una visión de la mujer como ser desvalido" (Gilbert, 1995: 30). Es indiscutible que si alguien administra drogas sin consentimiento a una persona para anular su conciencia y abusar de ella, este acto constituye una violación. Pero si alguien ofrece unas copas y seduce bajo los efectos del alcohol, ¿puede considerarse también una violación? Sin duda, las dos situaciones son muy distintas, pero el problema del ítem formulado por Koss era precisamente que su ambigüedad podía recoger situaciones de ambos tipos. Pero, ante todo, ¿por qué no se tenía en cuenta la opinión de las chicas clasificadas como agredidas y que no afirmaban haberlo sido? Según Koss y otras feministas, porque su falta de conciencia de género les impedía reconocerse a sí mismas como víctimas (Roiphe, 1994b: 109-110).

Dos periodistas del Blade (Periódico de Toledo, en Ohio) realizaron otro informe, el llamado Toledo Report (1993), a partir de las dudas suscitadas por los datos arrojados por el de Koss. Eliminaron la pregunta sobre la ingesta de drogas y alcohol y no incluyeron a las mujeres que no se veían a sí mismas como víctimas de violación. El resultado fue que la estadística pasaba de 1 de cada 4, a 1 de cada 22 o 23. Pero los estudiantes siguen barajando en sus mentes estadísticas desproporcionadas:

Lo que es increíble es que los estudiantes sigan creyendo actualmente que el $50 \%$ de las mujeres son violadas. Esta es la crisis real: que hay un número no insignificante de jóvenes mujeres con esa alarmante creencia. (Roiphe, 1994b: 58).

Lo más lamentable son las consecuencias políticas que se derivan de todo esto (Sommers, 1994, Gilbert, 1995; 1991). Mientras que grandes partidas económicas se destinan al levantamiento de centros de asistencia en campus universitarios, otras áreas más 
deprimidas con una tasa real muy alta de violación ${ }^{23}$ carecen de medios económicos para atender a sus víctimas. La afirmación de Andrea Parrot, de Cornell University ${ }^{24}$, de que "cualquier chica que sea psicológica o físicamente presionada para un contacto sexual en cualquier ocasión es tan víctima de violación como la que es atacada en las calles", es en todo caso una opinión que puede suscitar rechazo o no, pero las tasas reales de incidencia deberían ser las que determinasen, en última instancia, los recursos que hay que emplear para dar cobertura a este problema.

El fenómeno de las violaciones en los campus universitarios ha de ser estudiado desde dos ópticas. Por un lado, las concepciones sobre violencia y agresión sexual que subyacen en los acercamientos feministas a esta cuestión. El principal presupuesto teórico del feminismo es que la violación es un efecto más de la cultura patriarcal, de la dominación masculina que engendra violencia contra la mujer. Una de las afirmaciones más repetidas por las feministas es que la violación no es un acto criminal y violento en sí mismo, con una motivación meramente sexual, sino un ejercicio de poder de los hombres sobre el cuerpo de la mujer motivado por el odio sexista hacia ellas ${ }^{25}$. Con lo cual, la motivación de los jóvenes universitarios que subyace en las date rape sería atentar, en sus citas, contra la dignidad sexual de las jóvenes del campus, y no tanto dejarse llevar por un impulso exclusivamente sexual. De la misma manera, los problemas producidos en estos encuentros no tendrían nada que ver con problemas relacionados con la falta de comunicación y entendimiento entre jóvenes, ni con la educación sexual recibida, sino con una cuestión mucho más perversa derivada del carácter funcional del patriarcado.

Ya en la visión de Simone de Beauvoir sobre la iniciación al sexo en las mujeres podemos encontrar el origen de esta perspectiva, pues esta autora es clave para entender la epistemología feminista actual y su libro, El Segundo Sexo, sigue siendo un libro de obligada referencia para el feminismo:

La mujer es penetrada y fecundada a través de la intervención del varón; esta intervención siempre es una especie de violación (Beauvoir, 2005: 480).

No es raro que la primera experiencia de la joven sea una verdadera violación y que el hombre se muestre odiosamente brutal (...). En cualquier caso, hasta con el hombre más deferente y cortés, la primera penetración siempre es una violación (Beauvoir, 2005: 492).

\footnotetext{
${ }^{23}$ El informe Toledo también calculó que la tasa de violación en los campus era treinta veces más baja que en otras áreas más deprimidas como en Toledo y Ohio, para la población de chicas de edades comprendidas entre 18 y 22 años.

${ }^{24}$ Citado en Sommers (1994: 220). Andrea Parrot pertenece a la Cornell University Coalition Advocating Rape Education.

${ }^{25}$ De nuevo un argumento circular, que no explica por ejemplo, las violaciones de hombres. Éstas se producen con bastante frecuencia dentro de las cárceles americanas.
} 
Por otra parte, y dejando aparte la teoría feminista, si atendemos a las cifras de violaciones en los campus registradas oficialmente vemos que éstas se sitúan en torno a 1,5 víctimas por año, lo que nos impide hablar de una plaga de date rape (Roiphe, 1994b). Profundizando un poco más en este tema resulta interesante analizar el hecho de que las feministas "anti-date rape" defiendan que los encuentros sexuales deben ser regulados como un contrato ${ }^{26}$, mediante un acuerdo explícito en el que todo esté pactado: besar, tocar, acariciar, desvestir, y dichos actos sean precedidos de preguntas y respuestas explícitas al respecto, de manera que cualquier "no" sea siempre "no". Pero los "no" de las mujeres (y hombres) en un contexto sexual no siempre tienen la misma explicitud, intensidad o significado (Muehlenhard y Peterson, 2005; Muehlenhard y Hollabaugh, 1988), de la misma manera que la mayor parte de la gente no pide permiso a la hora de besar 0 tocar, pues todo ello forma parte del lenguaje no verbal de los encuentros sexuales. Esta afirmación es sin duda polémica, pero lo cierto es que dentro de un escenario sexual (en una cita) y entre dos personas que se atraen, el "no" forma parte de un juego donde se pone a prueba el deseo del otro; y en el peor de los casos, viene de un conflicto entre "querer" y "no querer" -que puede resolverse dentro de la situación erótica- y que es producto de inhibiciones o temores sexuales 0 incluso de estereotipos asociados a los roles esperados en ambos sexos. En ocasiones un "no" inicial puede transformarse en "sí" ante la excitación del otro y viceversa, un "si" inicial puede acabar en un fracaso. Sin embargo, apenas se habla de la "ambivalencia sexual" (Muehlenhard y Peterson, 2005) que opera en muchos encuentros sexuales entre hombres y mujeres (sobre todo jóvenes), y de los estudios que miden este tipo de comportamientos y actitudes, aun cuando la literatura al respecto es bastante amplia.

Conceptos como token resistance to sex (resistencia simbólica al sexo) que tiene lugar cuando se indica que no se quiere sexo y en realidad se tiene intenciones de tener un encuentro sexual, y los problemas relacionados con la falta de comunicación (miscommunication) o entendimiento (misunderstanding), fueron desarrollados a la par que surgieron los estudios sobre victimización sexual en la línea aquí descrita que emprendiera Koss. Uno de los estudios más significativos realizado sobre población universitaria llegó a la conclusión de que un $39 \%$ de chicas había dicho que "no" a un encuentro sexual cuando quería decir "si" (Muehlenhard y Hollabaugh, 1988), resultado que midieron preguntando a las entrevistadas si alguna vez habían vivido la siguiente situación:

Te encontraste con un chico que deseaba tener un encuentro sexual contigo y tú querías también, pero por alguna razón indicaste que no querías, aunque tuvieras realmente la intención de hacerlo y estuvieras lista para un encuentro sexual. En otras palabras indicaste "no" cuando querías decir "sí" (p.874).

\footnotetext{
${ }^{26}$ Un ejemplo radical sobre los pactos sexuales puede encontrarse en el código Antioch, que se ha hecho famoso por la rigidez de las reglas recomendadas a los universitarios de esta facultad de Ohio.
} 
También los hombres incurrían en esta actitud en una proporción incluso mayor que la de las mujeres ${ }^{27}$. Además, se midieron las contradicciones que los individuos identificaban entre el hecho de querer entablar una relación sexual pero no estar dispuesto a llevarla a la práctica, y entre no querer sexo pero estar dispuesto a tener una relación sexual. Es decir, en unos casos se daba un conflicto entre el deseo sexual y las consecuencias no deseadas del mismo (embarazo, riesgo de enfermedad, creación de un vínculo). En otros se deseaban las consecuencias (promoción de intimidad, satisfacción de las necesidades del otro, reducción de tensión en la pareja) pero no el encuentro sexual. En ambas situaciones el género de los entrevistados sí resultaba ser un factor significativo, pues el sexo unido a la culpa o al miedo a dañar la imagen personal era más frecuente en las mujeres, y el sexo como instrumento para ensalzar la imagen personal aparecía con más frecuencia en los hombres (Muehlenhard y Peterson, 2005).

Entonces, ¿cómo hacer para interpretar esta clase de señales que forman parte de los comportamientos de cortejo en cada contexto concreto? Teorizar aquello con lo que nos encontramos cotidianamente puede resultar mucho más difícil de lo esperado si se quiere hacer de manera honesta y rigurosa. En este sentido, otro concepto muy útil para analizar las relaciones interpersonales sin caer en explicaciones vacías es el de ignorancia plural (pluralistic ignorance) acuñado por Floyd Allport en los años treinta (Lambert, Kahn y Apple, 2003) y que se define como el fenómeno que ocurre dentro de un grupo cuando cada miembro cree que sus actitudes, juicios o creencias privadas chocan con la norma del grupo. De esta manera la gente actúa o se comporta en conformidad con la norma y en contradicción con su actitud privada, experimentando además, que son los únicos en afrontar este conflicto, cuando en realidad puede que el resto de los individuos se encuentre en la misma situación. Este mecanismo opera en muchos de los encuentros sexuales denominados hooking up (liarse o enrrollarse) mediante la presión experimentada de querer comportarse como creen que hacen los demás, afectando a un $42 \%$ de mujeres y un $46 \%$ de hombres (Lambert, Kahn y Apple, 2003). Es decir, todo el mundo piensa que el resto de la gente tiene líos y que es lo que se espera de ellos en un contexto de flirteo. Además, la incomodidad de ajustar su comportamiento a la norma percibida es experimentado por ambos sexos, solamente que los hombres creen en mayor medida que las mujeres, que el resto de los individuos de su mismo sexo no sienten esta disconformidad.

La polémica sobre los encuentros sexuales desatada por el feminismo va más allá cuando se afirma que en concreto los "si" de las chicas jóvenes quieren decir "no" (desestimando el caso contrario o que los chicos incurran en el mismo hecho) porque ha habido una coerción verbal, "una coerción sexual no violenta": "el consentimiento de una mujer a una actividad sexual no deseada a causa de la utilización por parte del hombre de argumentos que no incluyen las amenazas físicas" (Roiphe, 1994b: 67). Koss (2003)

\footnotetext{
${ }^{27}$ Un $43 \%$ de hombres frente a un 25\% de mujeres según el estudio de O'Sullivan y Allgeier (1994) y un $47 \%$ frente a un 38\%, en el de Sprecher et al., citado en Krahe, Scheinberger-Olwig; Kolpin (2000) y Husak y Thomas (2002).
} 
también lo denomina como coerción psicológica. Para Camilla Paglia éste es un concepto absurdo (Paglia, 2001: 90), y a las estudiantes universitarias se les repite una y otra vez este discurso, en lugar de aleccionarlas en la responsabilidad de sus actos, porque esto último es políticamente incorrecto:

Una chica que se deja caer borracha en una fiesta de la fraternidad está loca. Una chica que sube las escaleras a solas con un hermano de la fiesta de la fraternidad es idiota. Las feministas llaman a esto culpabilizar a la victima. Yo lo llamo sentido común. (Paglia, 1994: 51).

Frente a este concepto de coerción que presupone la asimetría de poder entre el hombre y la mujer (y la intervención, pues, del patriarcado), los anteriores estudios citados desarrollan el concepto de "conformidad" (compliance) definido como la aceptación de mantener relaciones sexuales que realmente no se desean (Krahe, Scheinberger-Olwig, y Kolpin, 2000) fruto de la complejidad psicológica de los individuos, como señalan estos autores, la discrepancia entre los investigadores estriba en definir si los conceptos de conformidad y resistencia simbólica están relacionados o no con la victimización sexual, es decir, si estos dos comportamientos aumentan la probabilidad de sufrir una agresión sexual. Lo cual, en todo caso, es diferente de la visión de los mismos como constituyentes de una agresión sexual por sí solos.

De todos modos, el debate de las violaciones en los campus no debe trasladarse fuera de este contexto. Pertenecen a una dimensión de la sociedad americana con unas peculiaridades que se han detallado y que de momento no ha surgido en Europa. Pero lo que no puede hacerse es transformar una estadística que predice que una de cada 4 chicas universitarias americanas sufrirá violación o intento de la misma (según la concepción aquí analizada) en otra bien diferente, que afirme que 1 de cada 4 mujeres sufrirán algún tipo de violencia sexual en su vida. Una parte del público americano asiente cuando la disidente más provocadora y que más furia desata en el feminismo emplea toda su acidez para afirmar que "cuando el feminismo no sabe distinguir el hermano borracho de la fraternidad de un maníaco homicida, tiene un problema" (Paglia, 2001: 88). Y el resto de la audiencia reacciona con virulencia contra cualquier posicionamiento teórico que critique o cuestione el discurso feminista.

\section{La voz de Camille Paglia}

La primera obra de Camille Paglia, Sexual Personae: Art and Decadence from Nefertiti to Emily Dickinson fue publicada en 1990, tras nueve años de rechazo y negativas de siete editoriales y cinco editores, hasta su aceptación finalmente en Yale University Press. Paglia genera controversia con su peculiar pensamiento y visión acerca del movimiento feminista y el movimiento de gays y lesbianas, junto con su denominada filosofía sexual pagana acerca de la verdadera naturaleza de las relaciones entre los dos sexos plasmada en el arte. Su posicionamiento libertario ante los problemas aquí analizados, como el de 
las date rape o el acoso sexual, ha desembocado en la admiración de muchos lectores pero también en el rechazo de los sectores más conservadores o más políticamente correctos, entre ellos, el feminismo.

Camille Paglia sostiene que la sociedad es construida como defensa contra la naturaleza y que la sexualidad y el erotismo surgen de esta compleja intersección entre naturaleza y cultura. El sexo es definido en Sexual Personae como una fuerza demónica que gobierna nuestro inconsciente, mientras que el amor es un instrumento occidental para defendernos del aspecto incontrolable de éste. Este hecho se relaciona, para Paglia, con la existencia de dos esferas distintas entre sí: la emocional o sexual y la esfera social. En la primera de ellas, la mujer es más poderosa que el hombre pues gobierna las emociones y la sexualidad -lo que ha quedado reflejado en el arte- mientras que en la segunda, es el hombre quien ha tenido históricamente más protagonismo; sin embargo, el feminismo las solapa continuamente al considerar que la mujer es víctima de opresión en los dos planos.

La conquista necesaria de la esfera social ha desembocado, según esta autora, en un exceso de regulación de lo personal y de lo sexual en nombre de la defensa de la mujer. Para la autora de Sexual Personae, los setenta echaron por tierra una serie de convicciones morales y celebraron una vuelta a la naturaleza y a los sentidos. Pero el riesgo que ello implicaba era asumido ${ }^{28}$. En la actualidad, sin embargo, predomina un estilo paternalista en el que gays y mujeres piden protecciones especiales. Ello implica volver al ideal de mujer que necesita protección y tutela, contra el cual lucharon tanto las feministas de la primera ola.

Una de las tesis que se extraen de su teoría pagana es que si no hay una comprensión correcta de la sexualidad humana no es posible realizar ningún análisis sensato de las cuestiones sexuales, y de los problemas asociados a las mismas, como la violencia. Ocurre que el feminismo -dice Paglia- niega el componente natural o animal de nuestra sexualidad, defendiendo una construcción social de la misma y liberando al sexo de algunas de sus fuerzas más primitivas. Este sexo "depurado y cortés" acaba con la comprensión en toda su dimensión del erotismo. La consecución de una igualdad jurídica no implica resolver la dualidad de los sexos, ni tampoco la confrontación entre los mismos, que emana de un plano más psicológico y emocional; "la igualdad política de las mujeres, totalmente necesaria y deseable, no va a remediar la separación radical entre los sexos que empieza y acaba en el cuerpo. Los sexos siempre se verán sacudidos por violentos accesos de atracción y repulsión" (Paglia, 2006: 53). Este enfrentamiento está pervertido, según Paglia, por la idea feminista de dominación sexual masculina, con la que muestra su desacuerdo, pues "la ideología victimista, una caricatura de la historia social, impide que la mujer reconozca su dominación en el reino más profundo e importante" (Paglia, 2001: 85).

\footnotetext{
${ }^{28}$ Para Paglia, cualquier encuentro sexual con un extraño o desconocido, ya sea entre heterosexuales 0 entre homosexuales, tiene un componente de riesgo que lo hace a la vez más excitante.
} 
La autora de Sexual Personae afirma que esta idea de dominación se ha asentado en Norteamérica, tras los setenta, sobre un determinismo social defendido por tres grupos: las feministas que quieren borrar cualquier referencia a la naturaleza, los profesores de literatura sin conocimientos científicos y absortos por el constructivismo francés y el activismo gay (Paglia, 2001: 70). Camille Paglia defiende que el verdadero agente dominador no es el patriarcado, sino la Naturaleza, con su tiranía procreadora que instrumentaliza a hombres y mujeres para perpetuar la especie, "el patriarcado al que rutinariamente se le culpa de todo, produjo la píldora de control de la natalidad que ha hecho más para liberar a la mujer que el propio feminismo" (Paglia, 2001: 95).

En cuanto a la violencia y el origen de ésta, afirma que "todos los caminos de Rousseau conducen a Sade" (Paglia, 2006: 42), el gran olvidado de los filósofos morales. Y sostiene que la agresividad es algo propio del hombre, "la violación es un modo de agresión natural que sólo puede controlarse mediante el contrato social" (p. 56). El feminismo se equivoca al afirmar que la violación no es un delito sexual, sino un delito de poder, pero "el sexo es poder y todo poder es inherentemente agresivo" (p. 56). Por tanto, no es la sociedad la que produce el delito, sino la que protege contra él. Y además, no debe confundirse lo descriptivo (que el hombre tenga impulsos violentos o que la violación sea un modo de agresión presente en nuestra naturaleza) con lo normativo (que por ello haya que liberar al hombre de culpa o de la responsabilidad que conlleva violar el pacto social). La crítica feminista del "biologicismo" de ciertos planteamientos asentados en fundamentos biológicos y evolutivos -como los que utiliza en ocasiones Paglia- proviene a menudo de esta confusión, que lleva incluso a rechazar el mismo concepto de diferenciación sexual.

Camille Paglia ha abanderado numerosas definiciones de su peculiar feminismo: un feminismo libertario, sin dependencias, sin protecciones, que expone en su ensayo No Rules in the Arena, y que reclama un nuevo paradigma de responsabilidad personal (antipaternalista). En este escenario, Paglia defiende a ultranza muchos de los aspectos contra los que lucha el feminismo, como la regulación de la prostitución, la no censura en materia sexual, y sobre todo el rechazo de las actuales visiones sobre la violación, el acoso y la pedofilia ${ }^{29}$. Camille Paglia quiere salvar al feminismo de las propias feministas, en una nueva concepción del feminismo como "movimiento internacional progresista, a favor del porno y antidogmático" (Paglia, 2001: 306). Esta mención del porno no es gratuita, ya que otro de los debates más controvertidos que tienen lugar fuera y dentro del feminismo es el de la conveniencia o no de la censura de todo aquello considerado como pornográfico, en el que Paglia se ha posicionado con fervor. Mas aún, para gran parte del sector feminista estadounidense, la pornografía está detrás de las violaciones de mujeres, y por tanto, sería necesario eliminarla de la sociedad. La polémica, como puede imaginarse, está en el conflicto planteado anteriormente en el caso de la educación, entre libertad de expresión y censura o regulación.

\footnotetext{
${ }^{29}$ En Estados Unidos se considera delito de pederastia, cualquier relación sexual consentida entre un mayor de 18 años y un menor de esta edad, por ejemplo, una relación entre alguien de 17 y 18 años sería de esta manera ilegal.
} 
Continuando con la personalidad de Paglia, ella se autodefine como "una feminista que quiere reformar radicalmente el feminismo actual para devolverlo al sentido común" (Paglia, 1992: 56); y que quiere recoger aquellos planteamientos que han sido excluidos de este movimiento:

El feminismo contemporáneo no comprende hasta qué punto ha silenciado a las mujeres y hombres disidentes. No lo comprende. Y así está completamente aislado en su torre de marfil y se siente impresionado cuando sale al mundo exterior y dice "¿Qué, qué? ¿Qué no estás de acuerdo con nosotras? Entonces tienes que ser una reacción contra nosotras" (Paglia, 2001: 359).

Camille Paglia habla de un feminismo pagano, estableciendo una paralelismo entre lo que religiosamente se denomina como corriente oficial u ortodoxa (que en este caso sería el feminismo establecido) y la línea subalterna y clandestina que ella abandera. También lo denomina Revamp feminism, estableciendo un juego de palabras con la significación de vamp ${ }^{30}$; un feminismo asentado en "la personalidad pagana de la vampira, la prostituta y la vagabunda, espíritus eróticos y hambrientos que se mueven con libertad" (p. 28). La mujer debe salir del paternalismo al que se ha visto sometida desde el código burgués del decoro y la amabilidad, ha de abandonar su estilo clasista comedido, suave, de mujer dulce y complaciente, en pos de la figura arcaica y nocturna de mujer combativa y sensual. Su teoría feminista demanda que "todas las feministas pro sexo, pro arte y pro belleza salgan del armario" y abracen un nuevo concepto: El Neosexismo o Nuevo sexismo:

Feminismo progresista que abraza y celebra todas las descripciones históricas de la mujer incluyendo las más escandalosamente pornográficas. Quiere mitología sin sentimentalismo y acepta todos los arquetipos, desde la madre a la bruja y la puta, sin censura. Admite y da la bienvenida al testimonio de los hombres. El nuevo sexismo pone la sensualidad en el centro de nuestra sensibilidad ante la vida y el arte (p. 196).

Por último, podemos concluir con la siguiente reflexión crítica de Camille Paglia, que sintetiza su pensamiento sobre la situación del feminismo en la actualidad, y que deja entrever el error en el que ha incurrido este movimiento en la construcción de su discurso:

Yo soy feminista pero estoy liberando al feminismo actual de estas falsas feministas que lo tienen ahora mismo atrapado en su garra mortal, que son antiporno y todo eso [...] porque, saben, el principal problema del feminismo durante los veinte últimos años ha sido que es incapaz de apreciar el arte ¿vale? No hay estética en el feminismo. Lo único que hay es un programa social (p. 357).

\footnotetext{
${ }^{30}$ La acepción más común es la de vampiresa o seductora sexual. Pero hay una segunda que proviene de la raíz francesa avant: lo que va en el frente o delante, la pieza de cuero del empeine de una bota que los zapateros solian reparar cuando éste se hacía viejo y que daría lugar al verbo revamp: renovar o salvar algo con maña. Además en el mundo del jazz, vamp significa improvisar, adornar e incrementar la diversión (Paglia, 2001: 28-29).
} 
Esta ausencia del arte y la estética es dañina para Paglia, ya que el arte es para ella -entre otras cosas- el canal que permite a la humanidad representar y dar salida a los conflictos que afloran en los límites difusos de la moral, al estar más allá de la dicotomía que ésta establece (entre lo bueno y lo malo). Una distinción maniquea que impregna, simplifica y dificulta, en el caso del feminismo, el entendimiento de las relaciones entre los dos sexos.

\section{Disidencia en Europa}

Hasta ahora hemos introducido el feminismo disidente de Norteamérica (sus principales autoras), pero ¿podemos afirmar que sucede algo parecido en Europa? Es cierto que en nuestro continente comienzan a escucharse intelectuales que lanzan opiniones similares a las disidentes norteamericanas o que se han hecho eco de estas autoras, como sucede en Francia con Elisabeth Badinter o con Empar Pineda en España ${ }^{31}$. Pero lo cierto es que este fenómeno no ha adquirido la misma dimensión que en EEUU (quizás porque no es un actor social y político con tanto peso en la esfera pública).

En Por Mal Camino, Badinter (2004) realiza un ejercicio de análisis de los estudios franceses sobre violencia de género muy parecido al que realiza Christina Hoff Sommers en su libro. De hecho, la autora francesa cita a esta autora en innumerables ocasiones y su libro es un intento de llevar a la práctica el mismo tipo de observación realizado por la autora americana para el caso francés. Gilles Lipovetsky, quien ha despertado muchas críticas por su modelo de "la tercera mujer", también arremete contra el victimismo feminista (Lipovetsky, 1999: 61-89) siguiendo a Sommers y Roiphe, en una obra más ecléctica que la de Badinter -que toma como único tema los excesos del feminismo contemporáneo- pero recapitulando muchos de los ejemplos norteamericanos de Sommers que posteriormente recogiera la filósofa francesa.

En España tanto los esfuerzos por alcanzar la paridad en el terreno político, como las recientes leyes contra la violencia de género y la reforma del Código Civil en materia de separación y divorcio, han suscitado polémica. Así, algunas mujeres que se definen como "las otras feministas", cuya portavoz es Empar Pineda (2006), se han levantado para clamar por "otro feminismo"32 que no comulga ni con la visión feminista centrada

\footnotetext{
${ }^{31}$ Este artículo fue escrito con anterioridad a la aparición de la obra de Edurne Uriarte, Contra el feminismo (2008), que está en la línea de las autoras disidentes. Sin duda, en España contamos con autoras que se alejan del mainstream feminista, tales como Raquel Osborne (por su posición en el debate sobre la prostitución, la pornografía y la censura) o Beatriz Preciado (por su visión del postfeminismo o del concepto de identidad sexual), entre otras. Sin embargo, creemos que no entran dentro de la categoría de feminismo disidente, definido como una crítica profunda al giro y a la actitud predominante en el feminismo, a la corrección política, así como un cuestionamiento de las tesis básicas feministas: que vivimos en un sistema de sexo/ género patriarcal originado socialmente y bajo unas estructuras de poder que mantienen tal sistema.

${ }^{32}$ Empar Pineda. "Un feminismo que también existe". (El País, 18-03-2006).
} 
en el género, ni con las consecuencias políticas que han generado sus demandas en la agenda pública; "hay un enfoque feminista que apoya determinados aspectos de la Ley Contra la Violencia de Género de los que nos sentimos absolutamente ajenas, entre ellos la idea del impulso masculino de dominio como único factor desencadenante de la violencia contra las mujeres" (Pineda, 2006).

Al igual que las feministas críticas americanas, Empar Pineda manifiesta su preocupación por un movimiento que acrecienta las tensiones y enemistades entre los sexos. También coincide en identificar en el feminismo institucional un giro conservador, que persigue y niega la prostitución, sin diferenciar entre las prostitutas que son obligadas a ejercer esta actividad y las que la ejercen por voluntad propia:

Finalmente, contemplamos con preocupación las posiciones del Instituto de la Mujer sobre la prostitución, a la que considera una actividad indigna y degradante. Estas ideas, en línea con el feminismo puritano de reforma moral de fines del XIX, brindan una excusa para mantener las pésimas condiciones en las que las prostitutas ejercen su trabajo. Las opiniones que venimos criticando nos parecen poco matizadas y excesivamente simplificadoras. Tienden a presentar a los hombres y a las mujeres como dos naturalezas blindadas y opuestas: las mujeres, víctimas, los hombres, dominadores.

En cambio, aboga por un feminismo igualitario, que deje de lamentarse por los daños sufridos en el pasado y se centre en el momento presente, en aquellos puntos donde las acciones positivas se destinen a acabar con cualquier situación discriminatoria 0 diferencial:

Desde nuestro punto de vista, el objetivo del feminismo debe ser acabar con las conductas opresoras y discriminatorias; debe ser conseguir la igualdad entre los seres humanos, no aniquilar a quienes discriminan u oprimen. Nosotras no deseamos un feminismo revanchista y vengativo, deseamos simplemente relaciones en igualdad, respetuosas, saludables, felices, en la medida en que ello sea posible, relaciones de calidad entre mujeres y hombres.

Si esto no ocurre así, entonces el feminismo andará Por Mal Camino. En esta obra Elizabeth Badinter llega a unas conclusiones muy parecidas a las que llega Sommers: la utilización de estadísticas -para presentar al hombre como un ser violento y a la mujer como una víctima- al servicio de una ideología: el feminismo (Badinter, 2004: 45). También critica el maniqueísmo que subyace en la visión feminista, en la que se presenta a los hombres como malos y a las mujeres como buenas. Todo ello conduce, además, al separatismo y al nacionalismo feminista, que ensalza las cualidades de las mujeres diferentes a las de los hombres, así como a una idealización de lo femenino (pp. 64-69) ${ }^{33}$.

\footnotetext{
${ }^{33}$ Badinter, que se proclama así misma feminista de la igualdad, y que fue discípula de Simone de Beauvoir, ha sido ya criticada por esta obra y tachada de antifeminista. En España, "las otras feministas" y su manifiesto también han recibido comentarios similares.
} 
Arremete además, contra el concepto feminista de dominación masculina, de naturaleza universal y ahistórica:

El eslogan implícito o explicito de "cambiar al hombre", más que el de "luchar contra los abusos de ciertos hombres", revela una utopía totalitaria [...]. Este concepto globalizador, que constriñe a hombres y mujeres en dos campos opuestos, cierra la puerta a toda esperanza de comprender su influencia recíproca y de medir su común pertenencia a la humanidad.

De la reflexión de la filósofa francesa podría extraerse la conclusión de que este discurso de la dominación, como entidad permanente, es el que permite al feminismo dotarse de vigencia y legitimar sus posiciones combativas a través de conceptos tan difusos como el mismo patriarcado. ¿Qué sucedería si la violencia, como plantean estas voces disidentes, no se debiera ni a la dominación ni al género? Al menos exclusivamente. Con total seguridad, el feminismo vería reducido su campo de actuación como movimiento social, al verse reducidos los intereses colectivos (la violencia no interesaría sólo a las mujeres sino a otros grupos afectados) y dejaría de experimentar una negatividad como grupo que es la que favorece la organización en torno a la lucha colectiva ${ }^{34}$. Si se ha alcanzado una igualdad jurídica (que pocos se atreverían a poner en duda) y se pone en cuestión la existencia de la dominación masculina, el feminismo tendría que reflexionar y reformular gran parte de sus reivindicaciones.

\section{Conclusiones}

El movimiento feminista se enfrenta a una fractura interna. Más aún, podríamos hablar con mayor acierto de un actor institucional más que de un movimiento social, aunque esta afirmación daría para una reflexión más amplia. Pero en definitiva, frente a las dificultades para movilizar a la sociedad y la complejidad de las cuestiones abordadas, la estrategia del feminismo -desvelada por las críticas aquí analizadas- ha sido con frecuencia la utilización partidaria y subjetiva de la realidad, bajo un prisma incuestionable: que vivimos bajo un sistema de sexo/género que nos oprime. Europa puede mirar hacia el caso americano para evitar incurrir en las mismas actitudes, y equivocaciones, que aquí hemos presentado; y porque históricamente se ha nutrido de su producción científica y teórica. En nuestro país las académicas españolas siempre han tomado como referencia a las autoras americanas

\footnotetext{
${ }^{34}$ Es un hecho demostrado en el campo de la acción colectiva que la construcción de un enemigo, sea éste real o imaginario, contribuye a la coordinación de las expectativas y las acciones del propio grupo, facilitando de este modo su actuación colectiva (Hardin, 1995; Miller, 2007). Por otra parte, los estudios que han medido los problemas de identificación de las mujeres con el feminismo, apuntan a que esto se debe en gran parte a que las mujeres no tienen una conciencia de género, ya que no comparten intereses colectivos ni experimentan descontento por falta de poder ni toman parte de acciones colectivas (Gurin 1985; Aronson, 2003).
} 
de la corriente principal y se han nutrido de los conceptos elaborados desde este lugar. Asimismo se han hecho eco de los libros con mayor impacto en EEUU. Esta realidad, choca con la falta de repercusión de las voces críticas o disidentes en nuestro país que, sin embargo, sí han logrado una fuerte audiencia en la sociedad americana y en otros países anglosajones. Por tanto, el feminismo corre el serio riesgo de ser absorbido por una sola de sus ramas, la más cultural y radical de todas ellas. Si esto ocurre así, sabremos "quién ha robado el feminismo".

\section{REFERENCIAS BiBLIOGRÁFICAS}

Aronson, P. 2003. "Feminists or post feminists?". Gender and Society 17: 903-921.

Audet, E. 2003. "Elisabeth Badinter desnaturaliza el feminismo para combatirlo mejor. Una crítica de Por mal camino", sisyphe.org. Artículo disponible en: http://sisyphe.org/article.php3?id_article=598. Traducido al castellano por "Ciudad de Mujeres".

Badinter, E. 2004. Por mal camino. Madrid: Alianza.

Beauvoir, S. 2005 [1949]. El segundo sexo. Madrid: Cátedra.

Bethea, A. R., K. R. Rexrode, A. C. Ruffo y S. D. Washington. 1999. "Violence in lesbian relationships: a narrative analysis". Poster presentado en el Encuentro Anual de la American Psychological Association: Boston.

Burton, A. 1992. "History is now: feminist theory and the production of historical feminisms". Women's History Review 1: 25-38.

Chesler. 2006. "The failure of feminism". The Chronicle of Higher Education Review 52: B12.

Chwe, M. 2001. Rational rituals: culture, coordination and common knowledge. Princeton: Princeton University Press.

Clark, V., S. Nelson Garner, M. Higonnet y K. Katrak (eds.) 1996. Antifeminism in the academy. Nueva York: Routledge.

Coleman, V. E. 1994. "Lesbian battering: The relationship between personality and the perpetration of violence". Violence and Victims 9: 139-152.

Duffy, M. 1992. "The Bete Noire of Feminism time". Time, disponible en: www.time.com/time/magazine/ article/0,9171,974660,00.html.

Daphne, P. 1999. Heterophobia: Sexual Harassment and the Future of Feminism. Lanham, MD: Rowman \& Littlefield.

Ebert, T. L. 1996. Ludic feminism and after postmodernism, desire, and labor in late capitalism. Ann Arbor. University of Michigan Press. 
Elster, J. 1982. Explaining technical change. Cambridge: Cambridge University Press.

Faludl, S. 1991. Backlash, The Underdeclared War Against American Women. Nueva York: Doubleday.

Farrell, W. 1986. The myth of male power. Nueva York: Berkley.

Farrell, W. 1993. The Liberated man. Nueva York: Berkley.

Fisher, B.S. y F. T. Cullen. 2000. "Measuring the sexual victimization of women: evolution, current controversies, future research", en Duffee, D. (ed.), Criminal Justice, Vol. 4, Measurement and analysis of crime and justice. pp. 317-390. Washington: DC, U.S. Department of Justice, National Institute of Justice.

Flanders, L. 1994. "The Stolen Feminism Hoax: Anti-Feminist Attack Based on Error-Filled Anecdotes", FAIR, artículo disponible en: $h$ ttp://www.fair.org/index.php?page=1246.

Gelb, J. 2006. "Backlash in the US and Japan". Comunicación presentada en el panel del comité RC 19 del congreso de IPSA. Disponible en: ipsa-rc19.anu.edu.au/Gelb.ipsa06.pdf.

Gilbert, N. 1998. "Realities and mythologies of rape". Society 35: 4- 10.

Gilbert, N. 1991. "The phantom epidemic of sexual assault". Public Interest 10: 54-65.

Gilbert, N. 1995. Was It rape? An examination of sexual assault statistics. Menlo Park: California, Henry J. Kaiser Family Foundation.

Gurin, P. 1985. "Women's gender consciousness". Public Opinion Quarterly 49: 143-63.

Harding, S. 1996. Feminismo y ciencia. Madrid: Ediciones Morata.

Husak, D. y G. Thomas .1992. "Date Rape, Social Convention and Reasonable Mistakes", Law and Philosophy 11: 5-126.

Kaminer, W. 1990. A fearful freedom: women's flight from equality. Nueva York: Addison Wesley Publishing.

Koss, M.P. y S.L. Hamby. 2003. "Shades of gray: a qualitative study of terms used in the measurement of sexual victimization". Psychology of Women Quarterly 27: 243-255.

Koss, M.P. y R. Warshaw. 1988. I Never Called It Rape: The Ms. Report on Recognizing, Fighting and Surviving Date and Acquaintance Rape: Ms. Magazine/Sarah Lazin Books.

Koss, M.P. y C. A. Gidycz .1985. "The sexual experiences survey: reliability and validity". Journal of Consulting and Clinical Psychology 53: 442-443.

Koss, M.P., C.A. Gidycz y N. Wisniewski.1987. "The scope of rape: incidence and prevalence of sexual aggression and victimization in a national sample of higher education students". Journal of Counselling and Clinical Psychology 55: 162-170.

Koss, M. P. y C. Oros .1982. "Sexual experiences survey: A research instrument investigating sexual aggression and victimization". Journal of Consulting and Clinical Psychology 50: 455-457. 
Krahe, B., R. Scheinberger-Olwig, y S. Kolpin. 2000. "Ambiguous Communication of Sexual Intentions as a Risk Marker of Sexual Aggression”. Sex Roles 42: 313-337.

Kurtz, S. 2001. "Silencing Sommers. Clinton holdovers have their way with HHS". The National Review, disponible en: http://www. nationalreview.com/contributors/kurtz120501.shtml.

Laframboise, D. 1996. Princess at the window: a new gender morality. Toronto: Penguin Books.

Lambert, T. A., A. S. Kahn y K. J. Apple. 2003. "Pluralistic ignorance and hooking up". Journal of Sex Research 40: 129-133.

Lehrman, K. 1997. The lipstick proviso: women, sex and power in the real world. Nueva York: Doubleday.

Lerner, R., A. K. Nagai y S. Rothman.1995. Molding the good citizen. The politics of high school history texts. Westport: Praeger.

Lipovetsky, G. 1999. La tercera mujer. Barcelona: Anagrama.

Mackinnon, C. 1993. "Feminism, marxism and the state". Signs 8: 43-58.

Miller, L. M. 2007. “Coordinación y acción colectiva”. Revista Internacional de Sociología 46: 161-182.

Muehlenhard C. L. y L. C. Hollabaugh .1988. "Do women sometimes say no when they mean yes? The prevalence and correlates of women's token resistance to sex". Journal of Personality and Social Psychology 54: 872-879.

Muehlenhard, C. L. y Z. D. Peterson. 2005. "Wanting and not wanting sex: the missing discourse of ambivalence". Feminism and Psychology 15: 15-20.

O'Sullivan, L. F. y E. R. Allgeier. 1994. "Disassembling a stereotype: Gender differences in the use of token resistance". Journal of Applied Social Psychology 24: 1035-1055.

Paik, A., E. O. Laumann y M. Van Haitsman. 1999. Sexual jealousy, violence and embeddedness in intimate relations: a social structural cultural explication, Chicago: Universidad de Chicago.

Page, S. 2006. "Feminism and the third wave: politicising the sociology of religion?". e-paper n. ${ }^{0} 17$. Comunicación presentada en la University of Leeds: UK.

Paglia, C. 2006. Sexual personae. Madrid: Valdemar.

Paglia, C. .2001. Vamps and tramps. Madrid: Valdemar.

Paglia, C. 1992. Sex, art, and American culture. Toronto: Vintage Books.

Patai, D. 1998. Heterophobia: sexual harassment and the future of feminism, Natlonal Book Network.

Patai, D. 2000. "Speak freely". Chronicle of Higher Education 46. 40. pB7, 2p, 2c.

Patai, D. 2003. "The great tattling scares on campuses". Chronicle of Higher Education 49: pB11, 2p. 
Pineda, E. 2006. "Un feminismo que también existe". El País, disponible en: http://www.pensamientocritico. org/emppin0306.htm.

Ravitch, D., E. Chester y Jr. Finn. 1987. What do our 17-year-0lds know? A report on the first national assessment of history and literature. Nueva York: Harper and Row.

Renzetti, C.M. 1988. "Violence in lesbian relationship. A preliminary analysis of causal factors", Journal of Interpersonal violence 3: 381-399.

Roiphe, K. 1994a. "Date rape's other victim”. New York Times Magazine: Nueva York.

Roiphe, K. 1994b. The morning after. Sex, fear and feminism. Boston: Back Bay Books.

Schoenberg, N. y S. Roe. 1993. "The Making of an Epidemic. A Three-Day Series". Toledo: Blade.

Simon, R. 1995. Neither victim nor enem: Women's Freedom Network looks at gender in America. Nueva York: Women's Freedom Network , University Press of America.

Sommers, C.H. 1994. Who stole feminism? How women have betrayed women. Nueva York: Touchstone.

Sommers, C.H. 1995. "Christina Hoff Sommers reply to charges disseminated by the left wing media watchdog group FAIR, disponible en: http://www.debunker.com/texts/fair2.html

Sommers, C.H. 2001. La Guerra contra los chicos. Como un feminismo mal entendido está dañando a los jóvenes. Madrid: Ediciones Palabra.

Sprecher, S., E. Hatfield, A. Cortese, E. Potapova y A. Levitskaya. 1994. "Token resistance to sexual intercourse and consent to unwanted sexual intercourse: College students' dating experiences in three countries". Journal of Sex Research 31: 125-132.

Steinem, G. 1995. Revolución desde dentro. Un libro sobre la autoestima. Barcelona: Anagrama.

Stinchcombe, A. L. 1970. La construcción de las teorías sociales. Buenos Aires: Ediciones Nueva Visión.

The National Coalition of Anti-Violence Programs .1998. Annual Report on Lesbian, Gay, Bisexual, Transgender Domestic Violence, disponible en: http://www.lambda.org/dv97.htm.

Uriarte, E. 2008. Contra el feminismo. Madrid: Espasa.

Wolf, N. 1991. El mito de la belleza. Barcelona: Emecé.

Young, C. 1999. Ceasefire: why women and men must join forces to achieve true equality. Nueva York: Free Press. 
ANA LEÓN MEJIA es Licenciada en sociología por la Universidad de Salamanca y doctoranda de la Universidad Autónoma de Barcelona. En la actualidad disfruta de una beca del Ministerio de Ciencia e Innovación (FPU) adscrita al Instituto de Estudios Sociales Avanzados (IESA-CSIC) y es investigadora visitante en el Departamento de Sociología y Filosofía de la Universidad de Exeter (Reino Unido). Entre sus trabajos más recientes cabe destacar "El rol de las creencias en contextos estratégicos", Cuadernos Económicos del ICE, $n^{0}$ 77, 2009 (con Luis Miller), y "The devil is in the details: Sex differences in simple bargaining games", Jena Economic Research Paper Series, 2007-069 (con Luis Miller).

RECIBIDO: $15 / 02 / 07$

ACEPTADO: $13 / 12 / 07$

Published online: 22 Mayo de 2009 